\title{
The Use of a Nanoscale Copper Catalyst in the Catalytic Decomposition of Water Polluted with Organic Dyes
}

\author{
Samia A. Kosa \\ Chemistry Department, Faculty of Science, King Abdulaziz University, Jeddah, Saudi Arabia \\ Correspondence should be addressed to Samia A. Kosa; skousah@kau.edu.sa
}

Received 16 June 2013; Revised 24 July 2013; Accepted 30 July 2013

Academic Editor: Zhenhui Kang

Copyright (C) 2013 Samia A. Kosa. This is an open access article distributed under the Creative Commons Attribution License, which permits unrestricted use, distribution, and reproduction in any medium, provided the original work is properly cited.

A supported copper catalyst was used as a catalyst for the decomposition of organic dyes using a commercial chlorinating agent. The catalytic process achieved complete decomposition in only $2 \mathrm{~min}$. Different catalyst to dye concentration ratios is studied to determine the optimal conditions. The catalyst is fully characterized using XRD, SEM, and EDX analysis.

\section{Introduction}

The removal of organic and inorganic pollutants is an aim shared by many researchers throughout the world [1-6]. Polluted water has led to many environmental issues and hazardous effects, including health effects on humans and many aquatic organisms [7-10]. Heavy metals are commonly removed by adsorbents and ion exchangers to ensure total removal [11-14]. The situation is somewhat different for organic pollutants because it is nearly impossible to remove $100 \%$ of organic pollutants from an aqueous stream through adsorption processes. In addition, industrial waste water containing large amounts of organic pollutants will require an enormous amount of adsorbent, which will again require environmentally safe removal. In this case, the catalytic decomposition of organic pollutants may be the best choice to remove these pollutants [15-20]. Photocatalytic decomposition is a commonly used removal method $[15,16]$, but this system is mainly used at lab scale because the whole system should be subjected to ultraviolet irradiation for a long period of time, making large-scale implementation difficult. Environmentally safe oxidants such as hydrogen peroxide are also used either as catalysts or to promote thermal decomposition [21]. The use of hydrogen peroxide is also limited by the fact that it is considered to be a mild oxidant, meaning that even in catalytic decomposition it will not totally decompose the organic pollutants into $\mathrm{CO}_{2}$ and $\mathrm{H}_{2} \mathrm{O}$, potentially resulting in more organic pollution fragments.
The use of excited molecular oxygen may be the solution to this problem. For example, singlet oxygen has distinct properties that enable it to be highly reactive, achieving total decomposition of the organic pollutant. The fact that the reaction of singlet oxygen is considered to occur via a freeradical mechanism means that the decomposition will occur in only a few minutes.

This study reports the removal of organic dye (pollutants) with a system consisting of a $5 \%$ solution of sodium hypochlorite (commercial grade), oxygen gas, and a supported copper oxide catalyst to generate singlet oxygen.

\section{Experimental}

2.1. Materials. Methyl orange (Merck), sodium hypochlorite solution (commercial), oxygen gas (99.99\%), aluminum hydroxide (Merck), and copper nitrate trihydrate (Merck) were used in these experiments.

2.2. Catalyst Preparation. First, aluminum hydroxide was calcined at $550^{\circ} \mathrm{C}$ for 3 hours to convert it into $\mathrm{Al}_{2} \mathrm{O}_{3}$. Copper was loaded as copper nitrate $(20 \%)$ on the resulting gamma alumina by impregnation with stirring for $2 \mathrm{~h}$ and then dried and calcined at $450^{\circ} \mathrm{C}$ for 3 hours.

2.3. Reaction Design. Oxygen was introduced to a $0.5 \mathrm{~mL}$ solution of $5 \%$ sodium hypochlorite at $100 \mathrm{ppm}$ from methyl 


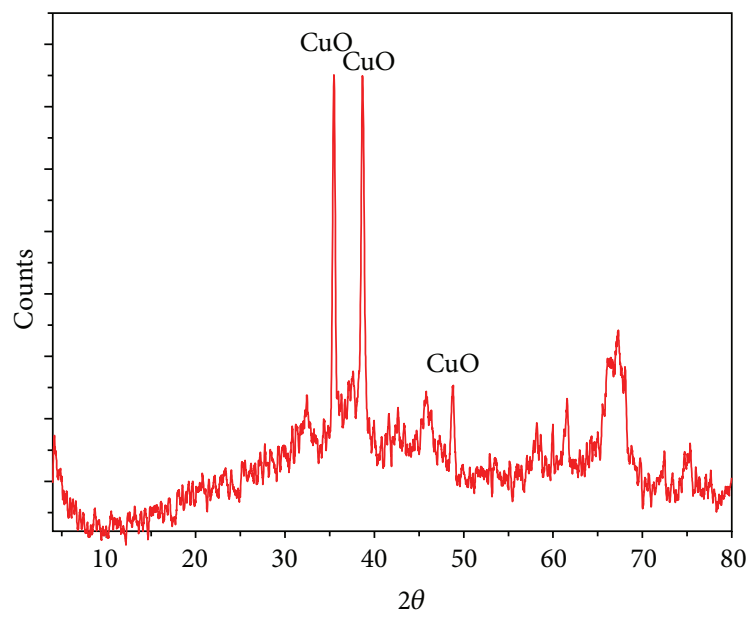

FIGURE 1: XRD of $\mathrm{CuO}$ catalyst deposited on alumina.

orange by passing oxygen at $20 \mathrm{~mL} / \mathrm{min}$ in an open system. Copper oxide catalyst was added ( $0.5 \mathrm{~g})$, and samples from methyl orange were collected and separated by centrifuge at several time points for analysis. For comparison, the same reaction was performed with and without catalyst and with and without oxygen.

\subsection{Instruments and Techniques}

2.4.1. X-Ray Diffraction Analysis (XRD). X-ray diffractograms of the samples under investigation were collected using a Bruker D8 Advance instrument with $\mathrm{CuK} \alpha 1$ radiation and a secondary monochromator operated at $40 \mathrm{kV}$ and $40 \mathrm{~mA}$.

2.4.2. SEM and EDX Analysis. Scanning electron microscopy (SEM) images were collected and EDX analysis was performed using a JXA-840 Electron Probe Micro Analyzer (JEOL).

2.4.3. Total Organic Carbon. Organic carbon content was measured using a Multi N/C total organic carbon measurement instrument (Analytik Jena, model 2100/2100 S).

\section{Results and Discussion}

3.1. XRD. The XRD patterns of the supported $\mathrm{CuO}$ catalyst over alumina are shown in Figure 1. This figure clearly shows that a pure phase of $\mathrm{CuO}$ was formed over an amorphous phase of gamma alumina.

3.2. SEM and EDX. Figure 2 shows the SEM image of the $20 \mathrm{wt} \% \mathrm{CuO} / \mathrm{Al}_{2} \mathrm{O}_{3}$ catalyst. This image clearly shows that the $\mathrm{CuO}$ crystals appear as separated aggregates at different intervals over the alumina surface. The EDX analysis of these aggregates (Figure 3 ) showed that these aggregates are mainly composed of $\mathrm{CuO}$.

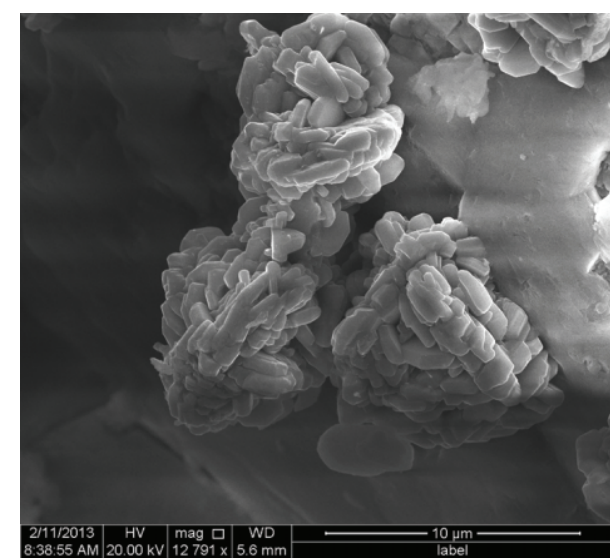

Figure 2: SEM of $\mathrm{CuO}$ on alumina.
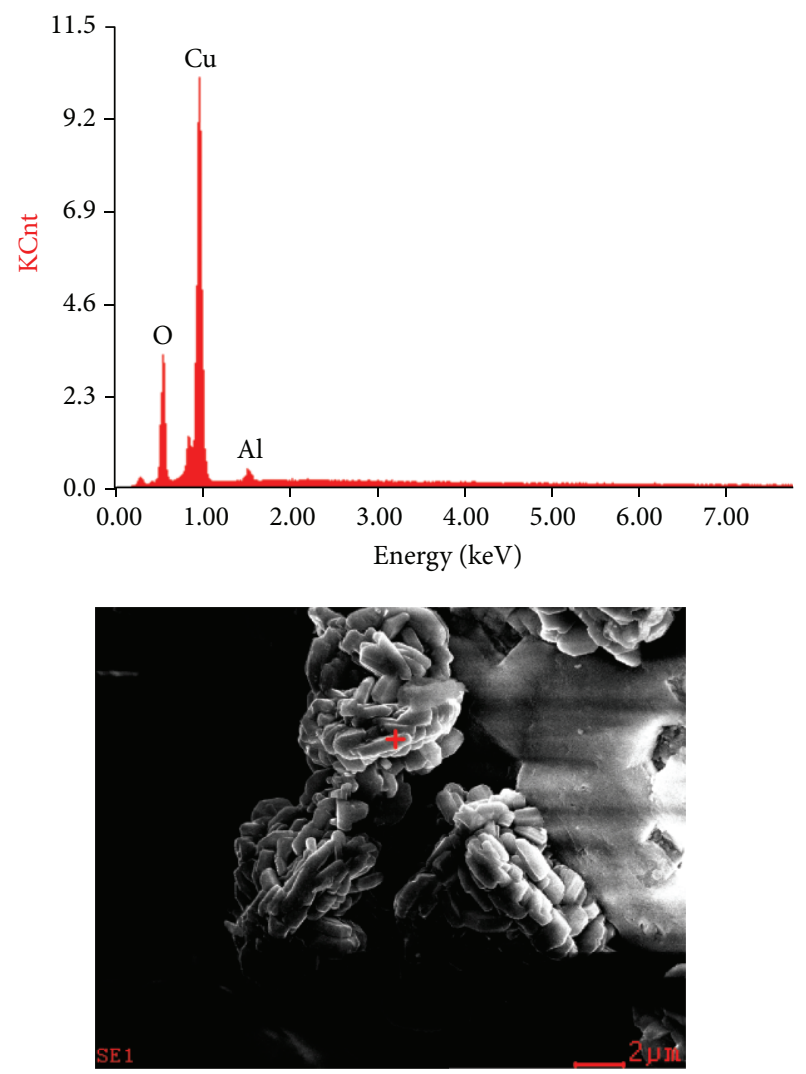

FIgURE 3: EDX spectra of $\mathrm{CuO}$ agglomerates.

3.3. Catalytic Decomposition of Organic Dye. Figure 4 shows that the rate of catalytic decomposition of the copper catalyst with chlorate solution and oxygen is much higher than that of the chlorate solution alone and that passing oxygen with catalyst in the absence of chlorate does not promote decomposition.

The previous results can be explained in light of the mode of decomposition of the dye. Passing oxygen without chlorate, even in the presence of a catalyst, does not induce decomposition because molecular oxygen is stable under 


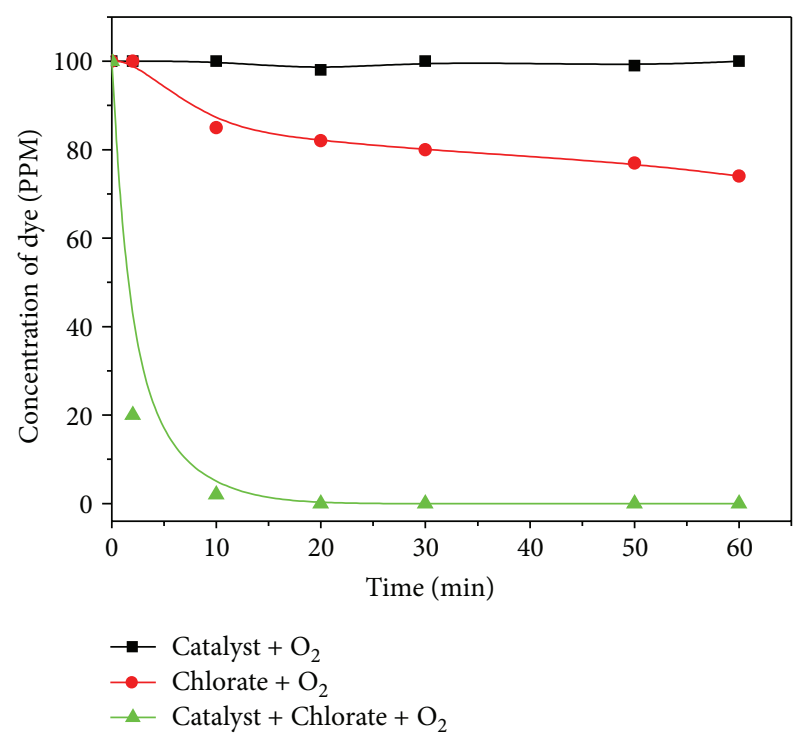

FIGURE 4: Comparison of the catalytic decomposition activity of catalyst with oxygen only, chlorate solution with oxygen, and catalyst with oxygen and chlorate.

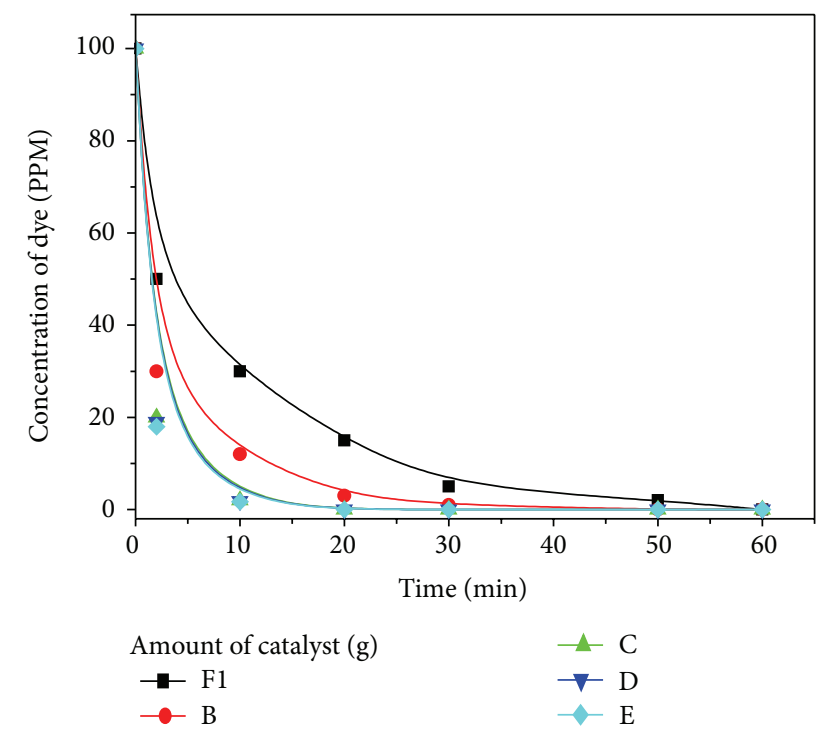

FIGURE 5: Effect of the amount of catalyst on the decomposition of the dye.

these conditions, and it is very difficult to decompose the dye at room temperature.

In the presence of chlorate solution (5\% sodium hypochlorite), the decomposition will occur according to the following equation:

$$
4 \mathrm{NaClO}+2 \mathrm{H}_{2} \mathrm{O} \longrightarrow 4 \mathrm{Na}^{+}+4 \mathrm{OH}^{-}+2 \mathrm{Cl}_{2}+\mathrm{O}_{2}
$$

The nascent oxygen produced in the previous equation could be used in the oxidation of the organic dye, and the $\mathrm{Cl}_{2}$ produced could also decolorize the dye [22]. In the combined presence of the catalyst, oxygen, and chlorate, a sudden effervescence of a huge amount of gases occurs, and depolarization can be visually observed in only a few minutes. This can only be explained by assuming that a singlet oxygen is produced and that the dye acts as a sensitizer [23]. However, because the concentration in Figure 3 was calculated by the UV-Vis spectra, the decolorization and decomposition cannot be differentiated. To differentiate between these outcomes, a sample after $60 \mathrm{~min}$ of reaction was measured for the total organic carbon (TOC), and the results showed that in the presence of catalyst, chlorate, and oxygen, the organic carbon is nearly absent after $60 \mathrm{~min}$.

Figure 5 compares the effects of different catalyst amounts on the decomposition of the organic dye. This curve clearly shows that optimal catalysis is achieved at $0.5 \mathrm{~g}$ of catalyst.

\section{Conclusions}

The following conclusions can be drawn from the research presented previously.

(1) The system of a copper catalyst, a solution of commercial chlorate, and any organic dye pollutant could be effective in the decomposition of organic pollutants.

(2) The aforementioned system can be easily scaled up at low cost to achieve effective pollutant removal.

(3) The decomposition followed a free-radical reaction mechanism and produced singlet oxygen.

\section{References}

[1] D. Zadaka, Y. G. Mishael, T. Polubesova, C. Serban, and S. Nir, "Modified silicates and porous glass as adsorbents for removal of organic pollutants from water and comparison with activated carbons," Applied Clay Science, vol. 36, no. 1-3, pp. 174-181, 2007.

[2] R. Allabashi, M. Arkas, G. Hörmann, and D. Tsiourvas, "Removal of some organic pollutants in water employing ceramic membranes impregnated with cross-linked silylated dendritic and cyclodextrin polymers," Water Research, vol. 41, no. 2, pp. 476-486, 2007.

[3] L. Hanchao, F. Suping, D. Xiaolin, Z. Nannan, and L. Yongli, "Comparison of three sorbents for organic pollutant removal in drinking water," Energy Procedia, vol. 5, pp. 985-990, 2011.

[4] Y. Lin, Y. Shi, M. Jiang et al., "Removal of phenolic estrogen pollutants from different sources of water using molecularly imprinted polymeric microspheres," Environmental Pollution, vol. 153, no. 2, pp. 483-491, 2008.

[5] T. S. Jamil, H. H. Abdel Ghafar, H. S. Ibrahim, and I. H. Abd El-Maksoud, "Removal of methylene blue by two zeolites prepared from naturally occurring Egyptian kaolin as cost effective technique," Solid State Sciences, vol. 13, no. 10, pp. 12932558, 2011.

[6] H. S. Ibrahim, T. S. Jamil, and E. Z. Hegazy, "Application of zeolite prepared from Egyptian kaolin for the removal of heavy metals: II. Isotherm models," Journal of Hazardous Materials, vol. 182, no. 1-3, pp. 842-847, 2010.

[7] J. L. Bryant, D. M. Clerico, J. N. Hicks, R. J. Trevino, and B. J. Bailey, "Environment committee: pollutants in our air, food, and water: effects on human health and the environment," Otolaryngology. Head and Neck Surgery, vol. 117, no. 2, pp. P56P7, 1997.

[8] A. Azizullah, M. N. K. Khattak, P. Richter, and D.-P. Häder, "Water pollution in Pakistan and its impact on public health-a 
review," Environment International, vol. 37, no. 2, pp. 479-497, 2011.

[9] C. J. Choi, J. A. Berges, and E. B. Young, "Rapid effects of diverse toxic water pollutants on chlorophyll a fluorescence: variable responses among freshwater microalgae," Water Research, vol. 46, no. 8, pp. 2615-2626, 2012.

[10] M. Neri, D. Ugolini, S. Bonassi et al., “Children's exposure to environmental pollutants and biomarkers of genetic damage: II. Results of a comprehensive literature search and meta-analysis," Mutation Research, vol. 612, no. 1, pp. 14-39, 2006.

[11] Y. S. Ok, J. E. Yang, Y.-S. Zhang, S.-J. Kim, and D.-Y. Chung, "Heavy metal adsorption by a formulated zeolite-Portland cement mixture," Journal of Hazardous Materials, vol. 147, no. 1-2, pp. 91-96, 2007.

[12] S. K. Pitcher, R. C. T. Slade, and N. I. Ward, "Heavy metal removal from motorway stormwater using zeolites," Science of the Total Environment, vol. 334-335, pp. 161-166, 2004.

[13] C. Wang, J. Li, X. Sun, L. Wang, and X. Sun, "Evaluation of zeolites synthesized from fly ash as potential adsorbents for wastewater containing heavy metals," Journal of Environmental Sciences, vol. 21, no. 1, pp. 127-136, 2009.

[14] F. Ji, C. Li, B. Tang, J. Xu, G. Lu, and P. Liu, "Preparation of cellulose acetate/zeolite composite fiber and its adsorption behavior for heavy metal ions in aqueous solution," Chemical Engineering Journal, vol. 209, pp. 325-333, 2012.

[15] M. E. Jenkin and K. C. Clemitshaw, "Ozone and other secondary photochemical pollutants: chemical processes governing their formation in the planetary boundary layer," Atmospheric Environment, vol. 34, no. 16, pp. 2499-2527, 2000.

[16] T. Mori, M. Takahashi, H. Nakajima, T. Fujimoto, and M. Watanabe, "Synthesis and photo-catalytic property of a hollanditetype compound $\left(\mathrm{K}_{2} \mathrm{Ga}_{2} \mathrm{Sn}_{6} \mathrm{O}_{16}\right)$," Journal of the European Ceramic Society, vol. 26, no. 4-5, pp. 583-587, 2006.

[17] G. Busca, M. A. Larrubia, L. Arrighi, and G. Ramis, "Catalytic abatement of $\mathrm{NO}_{x}$ : chemical and mechanistic aspects," Catalysis Today, vol. 107-108, pp. 139-148, 2005.

[18] M. E. Lindsey and M. A. Tarr, "Quantitation of hydroxyl radical during Fenton oxidation following a single addition of iron and peroxide," Chemosphere, vol. 41, no. 3, pp. 409-417, 2000.

[19] L. Gu, N. Zhu, H. Guo, S. Huang, Z. Lou, and H. Yuan, "Adsorption and Fenton-like degradation of naphthalene dye intermediate on sewage sludge derived porous carbon," Journal of Hazardous Materials, vol. 246-247, pp. 145-153, 2013.

[20] S. S. Watson, D. Beydoun, J. A. Scott, and R. Amal, "The effect of preparation method on the photoactivity of crystalline titanium dioxide particles," Chemical Engineering Journal, vol. 95, no. 1-3, pp. 213-220, 2003.

[21] P. Ratnasamy, D. Srinivas, and H. Knözinger, "Active sites and reactive intermediates in titanium silicate molecular sieves," Advances in Catalysis, vol. 48, pp. 1-169, 2004.

[22] K.-W. Kim, E.-H. Lee, D.-Y. Chung et al., "Manufacture characteristics of metal oxide-hydroxides for the catalytic decomposition of a sodium hypochlorite solution," in Chemical Engineering Journal, vol. 200-202, pp. 52-58, 2012.

[23] F. M. P. R. Van Laar, F. Holsteyns, I. F. J. Vankelecom, S. Smeets, W. Dehaen, and P. A. Jacobs, "Singlet oxygen generation using PDMS occluded dyes," Journal of Photochemistry and Photobio$\log y$ A, vol. 144, no. 2-3, pp. 141-151, 2001. 

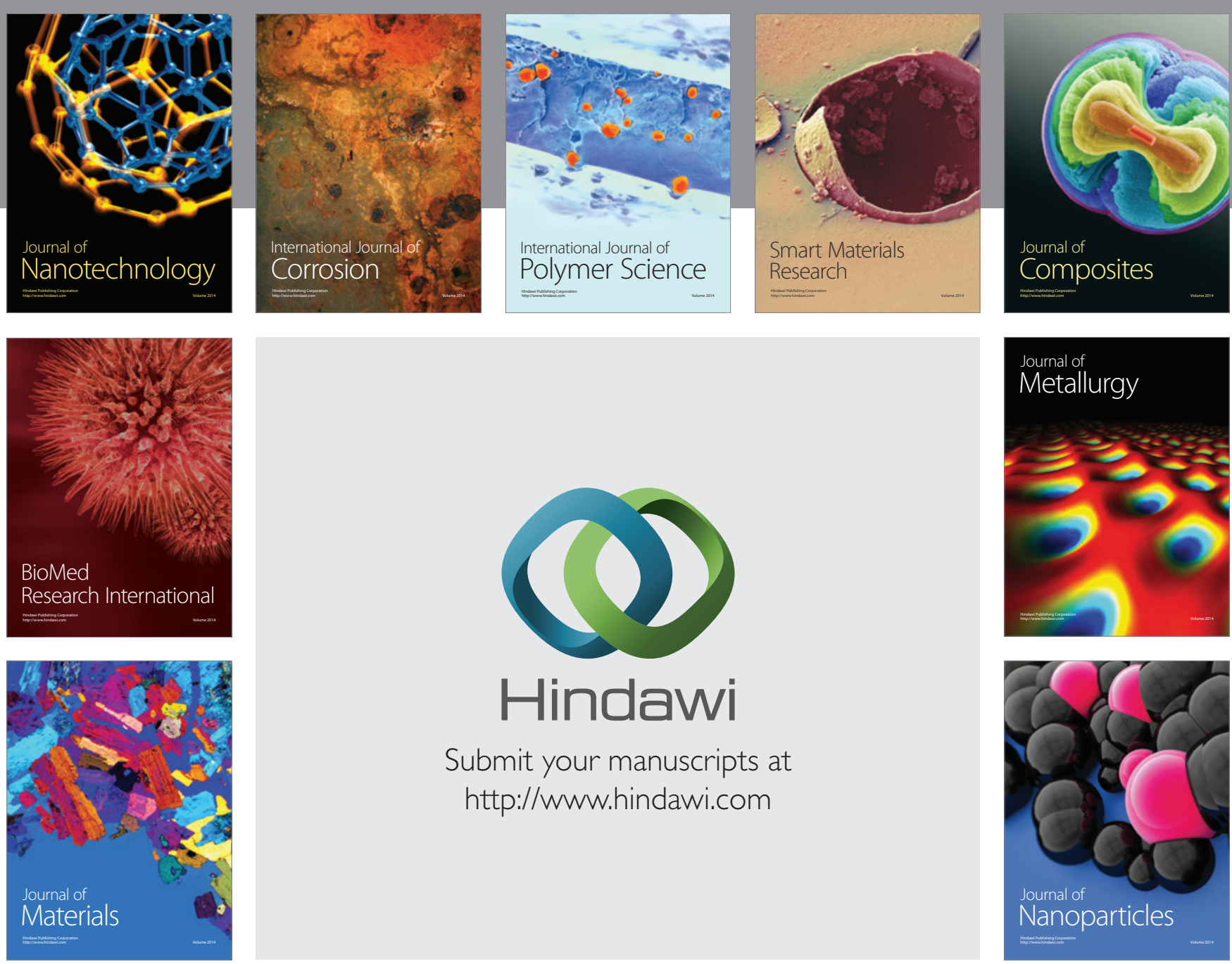

Submit your manuscripts at http://www.hindawi.com
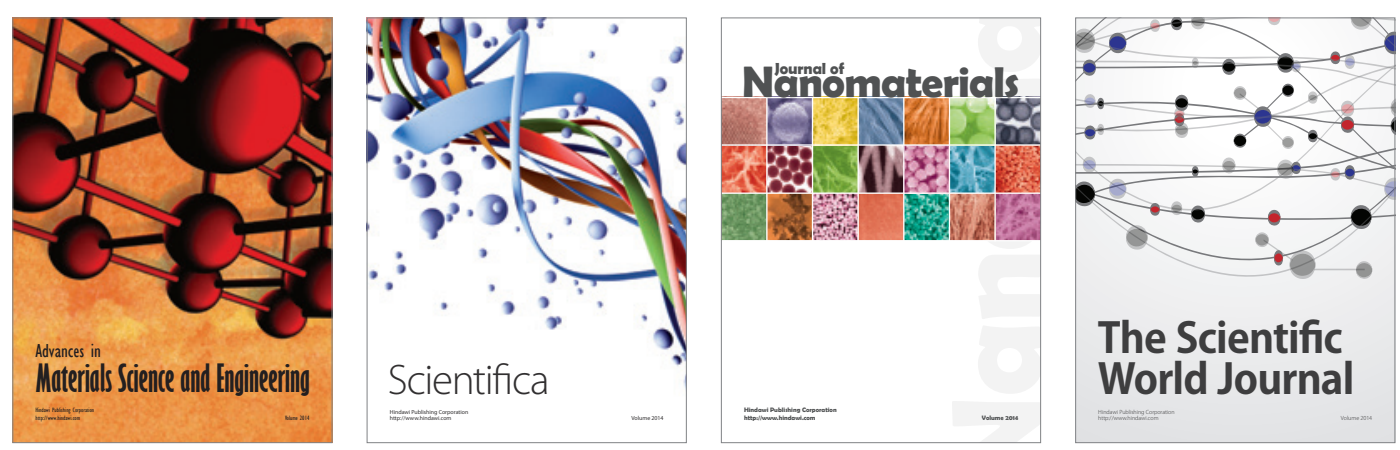

\section{The Scientific World Journal}
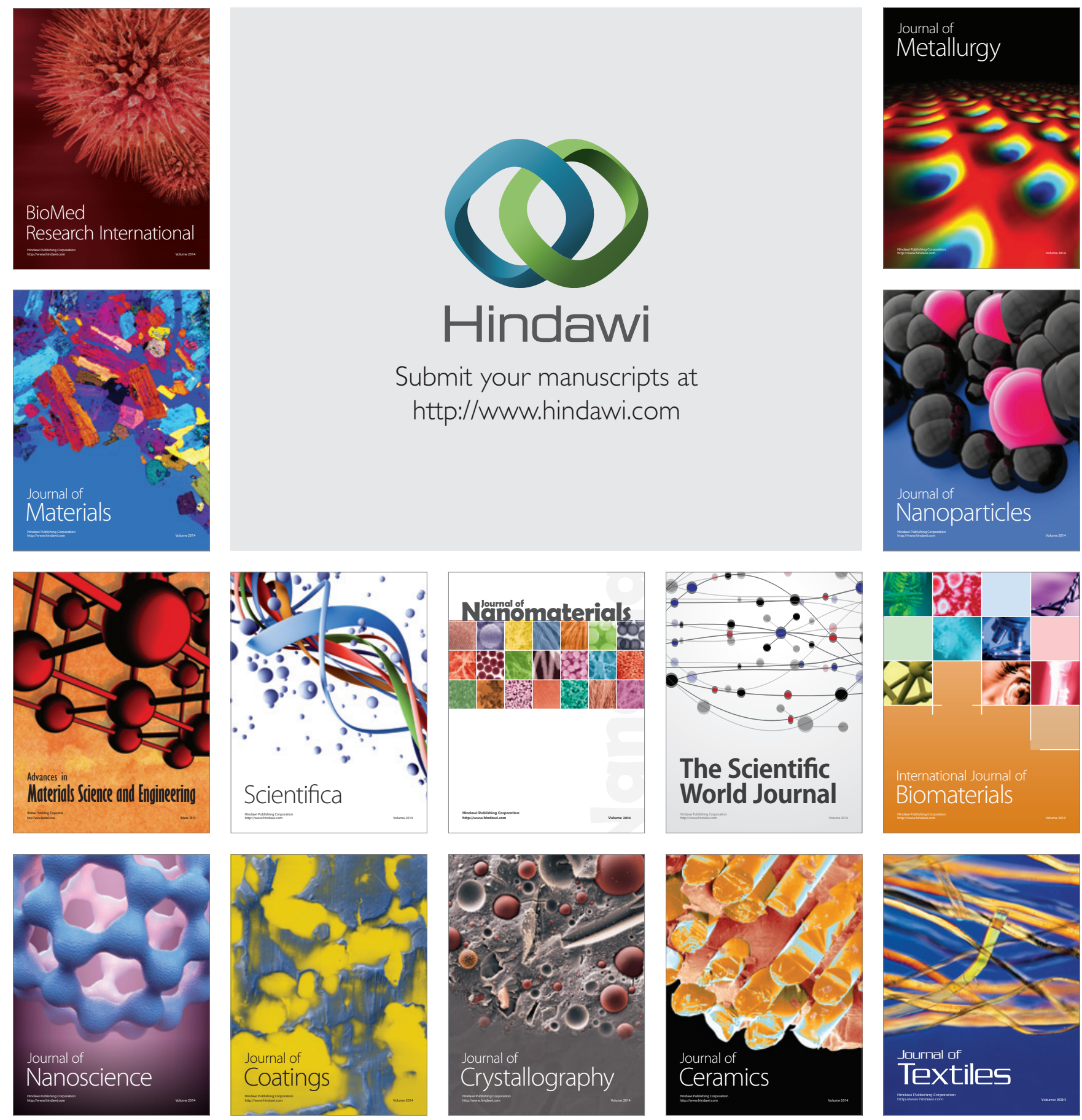